\title{
Psychological Peculiarities Pertaining to Conducting a Search of Adult Criminals and Juvenile Delinquents
}

\author{
Sadagat Gulmirzaevna Bashirova ${ }^{1^{\star}}$ \\ Artur Gasanguseynovich Ibragimov ${ }^{2}$ \\ ${ }^{1}$ Department of Theory and Methodology of Law Teaching, \\ Faculty of Law, Kazan Federal University \\ ${ }^{2}$ Department of Criminal Procedure and Criminalistics, \\ Kazan Federal University \\ ${ }^{*}$ Corresponding Author
}

Doi: $10.36941 /$ jesr-2019-0028

\begin{abstract}
The article discusses the problems of psychological preparation by an investigator to carry out a search and seizure as independent investigative actions. A quick and complete investigation of crimes depends on the skills and abilities of the investigator when applying methods of lawful mental influence on the person being searched. Psychological problems, questions of organizing the conducting a search are the objects of the works of M.I. Enikeeva, N.P. Yablokova, V.A. Obraztsova, V.I. Popova, A.S. Knyazkova, R.L. Ahmedshina, T.V. Averyanova, R.S. Belkina, Yu. G. Korukhova, E.R. Rossinskaya, etc. The purpose of this article is to consider the psychological nature of the search, to reveal a specific series of circumstances. In legal literature, a search is understood to mean not only search coercive activity, but also the cognitive activity of the investigator. Peculiarities of the investigator's cognitive activity are expressed in the personal perception of the searched premises and the personality of the most searched in a conflict situation. It should be noted that at the time of the search, the constitutional rights of citizens to privacy and the right to privacy of housing are limited. Therefore, compliance by the investigator with the procedural order of the search and the rule of law ensures the effectiveness of this investigative action, which in turn guarantees the observance of the constitutional rights of citizens.
\end{abstract}

Keywords: search psychology, searched, investigator, documents sought, seizure

\section{Introduction}

Psychologically, a search is an active, purposeful perception of searched premises and persons using information gathered in advance. During the search, the investigator must remember that the sought objects by the searched person are deliberately hidden and the effectiveness of the search in this case will depend on its focus, emotional stability and endurance. In addition to all circumstances, in the psychological aspect the investigator needs to activate the speech contact of the searched person. This will help him in solving several problems, namely: to monitor the reactions of the searched person, to carry out the conviction about the voluntary delivery of the items sought, to observe and find out the relationship of the detected objects with others, their significance for the searched person. In the search procedure, questions should be asked as actively as possible about the purpose of certain items, involving the searched person in this. The volume of speech, the pitch of the voice testifies to the internal state and, accordingly, gives out its actual attitude to the actions of the investigator.

These investigative actions are one of the main ones, since they form the evidence base for 
identifying the perpetrators of a crime. The results of the analysis of the materials of the cases under investigation indicate that the search is often carried out in the home of the suspect and the accused, close relatives and their entourage. Very often they try in every possible way to prevent the normal course of its conduct. Therefore, the search is compulsory, which is expressed in the restriction of the constitutional rights of citizens. Consequently, the investigator must strictly follow the norms of the law during the search, which in turn leads to the observance of the rights of citizens guaranteed by law. The application of these psychological requirements in the end, consistent with the objectives of the process and accelerates the process of collecting evidence in the case.

For the successful professional activities of the investigator, in addition to legal knowledge of the criminal law, the ability to apply psychological knowledgeis also required. With the help of this knowledge, he interacts and exerts a psychological effect on people with whom he, as a lawyer, has to contact in the conducting of investigative activities. This communicative competence is an external attribute in the professional activity of the investigator and at the same time is determined by his ability to establish psychological contact with the persons involved in the investigated case: the suspect, the accused, the victim, the witness.

When determining the most likely ways and places of shelter, it is important to pay attention to age, the profession of the person being searched. It should be borne in mind that it is typical for adult criminals to hide stolen jewelry, objects, money, depending on their criminal experience. Practice shows that they intentionally destroy traces that indicate the place of concealment (for example, age freshly painted planks of a cache). The investigator should also consider professional skills, hobbies and inclinations of a person. Often, depending on the urgency of the search, the investigator does not have time to study the psychology of the person hiding, which in turn makes it difficult to establish verbal contact with the searched person.

Unlike adults, juvenile delinquents are characterized by the use of two or more opposite directions when choosing the place and method of sheltering for the desired items. Such a place for stolen things can be easily accessible locations, such as a cache in a teenager's room or in a parents' room, where adults wouldn't have a chance to look. Therefore, the search action should be carried out in all rooms where the minor lives at the same time, it is necessary to conduct a personal search, since often the desired items can be in his (the searched).

In the presence of family control, juvenile offenders, as a rule, hesitate to keep the instruments of crime, objects and valuables obtained by criminal means in their homes, preferring to hide them in "no man's territory": in wastelands, cellars, barns, etc. If there is no proper control over the pastime of minors, the stolen property, various technical means for committing a crime, adolescents store directly in the apartment or in public places (Pakhomov, 2007).

During a search involving minors, the investigator needs to monitor his behavior, while taking into account the psychological aspect that a teenager, unlike an adult, is poorly able to control his feelings and emotions.

The investigator should ensure the highest possible concentration of attention, since focus on the object of inspection should be achieved in a variety of ways. The search itself is carried out in accordance with the principle of the "GFS" : to act gradually, feasibly, and systematically. After a thorough examination of one place of the search, the investigator proceeds to another without passing those that, in his opinion, look hopeless. He should not begin the search from the places where, from his point of view, the objects of the search should be located. If the inspection starts from the most "promising" places, it may be disappointing, and the search is unlikely to be successful (Kury \& Obergfell-Fuchs, 2015).

\section{Methods}

The methodological basis of this study is the dialectical method of scientific knowledge, as well as a set of general scientific and special methods of cognition. In the search, the investigator uses consistent and selective survey methods. The essence of the first method is that the searcher moves freely in a specific direction and at the same time considers adjacent sections.

Very often, during the search, the investigator uses the method of persuasion, which in turn 
helps him in solving several problems. In psychological science, this method is aimed at influencing the consciousness of the person (searched), which ensures the establishment of psychological contact between the investigator and the searched.

The conviction of the participants in the search is realized through various methods, such as empathy, suggestion, approval, etc.

The leading mental process in the search is observation. So, the concealment of an object in one figurine was found only when comparing it by weight with another similar figurine. In this case, the observation acquires a certain specificity - this is the so-called participating observation, included in the logic of the actions of the hiding person, the analysis of the phenomena here occurs as if "from the inside", from the point of view of the alleged actions of the hiding person. The effectiveness of observation is determined by the attitude to its tasks, the depth of awareness of perceptual actions, their focus and systematic nature, the inclusion of observation in the system of deductive inferences. The effectiveness of observation also depends on personal qualities, on the sphere of focus and concentration of the person making the search, on the features of his attention (Akhmedshin, 2015).

Observation as a method of studying the place of a search should be directed not only to individual objects, but also to the behavior of animals and birds, which can often be oriented towards the presence of a hiding person or the location of hidden things. Even more necessary is monitoring the behavior of the searched person, his relatives (Köhler et al., 2017).

\section{Results and Discussion}

The knowledge of the basics of psychology for the investigator is an important part of his work in all investigative actions. It should be noted that the effectiveness and speed of the search often depends on the psychological properties of the person. Such volitional qualities as courage, decisiveness or insolence can lead out of a stable state of a seeker. In this case, the effectiveness of the search depends on endurance, emotional stability, focus and stability of attention, which will help him see the likely behavior of the searched person at the time of the search. For this, the investigator must submit a psychological portrait of the person being searched.

In his article, R. L. Akhmedshin notes that a preliminary familiarization of the investigator with the personal characteristics of the participants in the investigation group will contribute to the subsequent optimization of the leadership of this group (Groall, 1992).

The cultural level, intelligence and education of the accused is also important to consider when looking for possible places and ways of shelter. If the criminal has knowledge in the field of physical and chemical qualities of certain objects, or understands the ability of a number of things to maintain their properties in adverse storage conditions, then we can assume that the cache will be created using this knowledge. Based on this, it can be assumed that the offender will hide the weapon in bulk products or, depending on the profession, will mask a cache, for example, an artist, hang a picture in the place where the cache is located.

It is desirable that the search take place in a calm, working environment. To do this, the investigator must remember the moral and ethical principles and be vigilant throughout the duration of the search. The absence of all these factors can cause a complex psychological atmosphere, which in turn can lead to undesirable consequences for both parties (the investigator and the searched person).

It is necessary to take into account the fact that sometimes the search is lengthy, and by the end the investigator gets tired and loses his vigilance, which prevents him from noticing small details, facts and phenomena. Therefore, the place of the search should be the strictest discipline, prohibiting outside conversations and other distracting actions.

So, from the foregoing, we can conclude that the main psychological qualities of the investigator are self-control and endurance. When conducting searches, often there are acute conflict situations when its participants are opposed by the accused, his friends and relatives. Often, people who are interested in the negative course of the search, try to do everything possible to prevent the positive end of the search. Interested parties quite often try to create a scandal and accuse law enforcement officials of unlawful actions, namely, a violation of their constitutional 
rights. At this moment, the main thing for the investigator is the timely stopped conflict actions. A law enforcement officer who has such qualities as calm, unwavering, emotional stability can easily cope in this situation. At the same time, he must not lose sight of the action of the searched person, in order, if necessary, to prevent a possible attack or the implementation of various tricks.

When conducting search actions, at the time of the search, one should take into account not only psychophysical manifestations, but also the reactions of the searched person regarding the actions of law enforcement officers. According to psychologists, his reactions are accompanied by rubbing his hands, coughing, exhaling relief or stopping his gaze at a specific place where the investigator carries out search actions. As for the unregulated will of the searched person, it can manifest itself in redness and blanching of the skin of the face, in trembling hands, stuttering or shortness of breath. If these signs appear in the suspect, a law enforcement officer can use them in order to achieve a positive search result.

\section{Summary}

An important part of the search is the preparation by the investigator of a plan for its conduct and recording of the results.

It is impossible to perceive the figure of the investigator in the context of the composition of the investigative group when conducting a search investigative action as the only one bearing a creative component figure (Ratinov, 2001).

Before starting a search, the investigator must be prepared for the fact that he may take a long time, and there is also the possibility of a negative result. This should in no way affect the determination of the success of the investigative action. Until the search is completed, it is too early to talk about its results, which means that search activity is carried out until absolutely all possibilities are realized (Abrahamsen, 1961; Anderson, 1990).

In addition to mental phenomena, the investigator is required to display organizational qualities, which in turn also affects the successful implementation of the search. It can be assumed that the organizational qualities of the investigator are:

a) endurance, discipline, self-esteem in relations with colleagues;

b) self-organization, which consists in quick orientation in the current situation and people;

c) exactingness, organizational abilities, providing leadership of various groups during the investigation of a criminal case (Chufarovsky, 2013; Greenawalt, 1989).

In our opinion, it is desirable that the participants in the search under the supervision of the investigator change the character of the investigative actions from time to time, taking into account a number of factors of the psychological nature of each participant individually.

\section{Conclusion}

Having examined the psychological characteristics of the investigator and the person being searched, it is worth noting that the effectiveness of the search is more dependent on the psychological and intellectual qualities of the person searching (the investigator).

In conclusion, it should be noted that in modern times, law enforcement officials need new recommendations for the search. It would be advisable if these recommendations are based on the achievements of psychological science. The prospect in this direction seems to be the study of individual psychological characteristics (primarily characterological) of those searched for to develop sets of recommendations for determining places for hiding items to be seized.

\section{Acknowledgements}

The work is performed according to the Russian Government Program of Competitive Growth of Kazan Federal University. 


\section{References}

Abrahamsen, D. (1961). The psychology of crime. NY, 156-159.

Akhmedshin, R. L. (2015). Tactical preparations for conducting search investigative actions upon arrival at the place of search. Tomsk State University Journal. State University, 398, 140-141.

Anderson, R. (1990). Human behavior in the social environment. N.Y., 87-91.

Chufarovsky, Yu. V. (2013). Legal Psychology. - M.: Prospect,. - 470 pages

Greenawalt, K. (1989). Conflicts of Law and Morality. Oxford University Press on Demand.

Groall, N. (1992). White collar crime. Buckingham, Philadelphia, 215-219.

Köhler, D., Scharmach, K., \& Geschichte der, Z. (2017). Rechtspsychologie in Deutschland unter besonderer Betrachtung der Sektion Rechtspsychologie des BDP. Praxis der Rechtspsychologie, 23, 455-468.

Kury, N., \& Obergfell-Fuchs, J. (2015). Rechtspsychologie. Stuttgart, 358 pages.

Pakhomov, S. N. (2007). Psychology of the Search [Text]. - M.: Yurayt, p. 241.

Ratinov, A. R. (2001). Psychology for Investigators [text]. M.: Yurlitinform, - p. 174. 